\title{
Pulse wave analysis
}

\author{
Michael F. O'Rourke,' Alfredo Pauca ${ }^{2}$ \& Xiong-Jing Jiang ${ }^{3}$ \\ ${ }^{1}$ UNSW, St Vincent's Clinic, Sydney, ${ }^{2}$ School of Medicine, Wake Forest University, Winston-Salem and ${ }^{3}$ Fu Wai Hospital, Beijing, China
}

\section{Introduction}

'Since the information which the pulse affords is of so great importance, and so often consulted, surely it must be to our advantage to appreciate fully all it tells us, and to draw from it every detail that it is capable of imparting' F.A. Mahomed 1872 [1]

It is now possible to generate the ascending aortic pressure wave from the arterial pressure pulse, recorded noninvasively by applanation tonometry in the radial or carotid artery. This represents a blend of nineteenth century sphygmography with cuff sphygmomanometry, and is made possible by introduction of high fidelity tonometers, by characterization of arterial hydraulic properties in the upper limb and neck, and through application of mathematical engineering techniques in modern computer systems. This review will consider historical development, theoretic background, present status and future potential, as well as comparing this technique with radial and carotid tonometry alone, and with analysis of flow pulse and volume pulse waveforms as determined by Doppler or photoplethysmographic techniques.

\section{Historical development}

The arterial pulse is the most fundamental sign in clinical medicine, and has since antiquity been identified with the physician and the art of medicine. Palpation of the pulse forms the crest of the Royal College of Physicians of London, which was established to improve the scientific basis and practice of medicine and in an era when William Harvey, as anatomist to that college, wrote his classic text 'de Motu Cordis...' [2]. William Bright [3] based his diagnosis of high blood pressure on 'hardness' of the pulse, and on the pressure required to extinguish the pulse. A scientific basis only arose after Marey [4], and then Mahomed [1] developed graphic methods to record the arterial pulse. By the beginning of the twentieth century, sphygmography was well established in medical journals

Correspondence: Professor M. F. O'Rourke, Medical Professorial Unit, St Vincent's Hospital, Victoria Street, Darlinghurst, NSW 2010, Australia. Tel.: 6I 2936 I 2350; Fax: 6I 2936 I 2385; E-mail: M.ORourke@unsw.edu.au

Received 22 November 2000, accepted I March 200 I. and in medical textbooks and had been used to describe heart block and effects of antianginal medication as well as hypertension and other conditions [5-9]. In life insurance examinations sphygmocardiography was widely used for detecting persons with 'arterial senility' and increased risk of premature death [10]. Unfortunately sphygmography lapsed with introduction of the cuff sphygmomanometer, which provided numbers for the extremes of the pulse, and a veneer of scientific accuracy.

Frederick Akbar Mohamed established the foundation of pulse wave analysis in a short medical lifetime from 1872 to 1884 . He described the normal radial pressure waveform and showed the difference between this and the carotid wave [1]. He showed the effect of high blood pressure on the radial waveform, and used the waveform to describe the natural history of essential hypertension, and the difference between this and chronic nephritis [7, 8]. He also described the effects of arterial degeneration with ageing on the arterial pulse [7]. These features were identified and utilized in the life insurance studies of the late nineteenth century [10].

Mahomed's sphygmogram, and the popular Dudgeon sphygmogram which followed, and which was used by Sir James MacKenzie [9] were mechanical devices, awkward to use and prone to artifact. Modern tonometer systems are piezo-electric and are far more accurate, reliable, and easy to use. While originally introduced clinically to measure intraocular pressure, they have been adapted for vascular use by Drzwiecki [11], Millar and others [5, 6].

While Mahomed was the first to recognize the difference between pressure waves in central and peripheral arteries, McDonald [12] was responsible for explaining this phenomenon on the basis of wave reflection, and for introducing transfer functions to characterize properties of vascular beds in the frequency domain, and (with his colleague J.R. Womersley) for establishing the validity of assuming linearity in the arterial tree [13]. The work of McDonald, Womersley, Taylor and others, originally from Harvey's own hospital (St Bartholomew's, London) has led on to the techniques described here for pulse wave analysis.

\section{Methods}

The technique of noninvasive aortic pulse wave analysis, as described here, depends on accurate recording of the radial 
pressure wave, its calibration against brachial pressure, then generation of the ascending aortic pressure waveform through use of a generalized transfer function in a computerized process. Ascending aortic waveforms are ensemble averaged into a single calibrated wave whose different features can be identified automatically with clinically important measures of pressure and time intervals measured and printed out in an interpretive report (Figure 1). Steps in the process are described below.

\section{Pressure recording}

Accurate applanation tonometry requires that the artery be applanated (flattened) underneath the sensor. This requires pressure from the operator with the vessel supported behind by the radius bone at the wrist or vertebral column and ligaments in the neck $[14,15,16]$. Complete confidence is gained when the device is applied to the eyeball to measure ocular pressure, or to an exposed artery, and where applanation can be confirmed visually. Reasonable confidence is gained if the pressure waves are completely consistent, beat to beat, if amplitude is the greatest that can be achieved, and if the pulse wave measured has the same character as one would expect in the artery i.e. sharp upstroke, straight rise to the first systolic peak, a definite sharp incisura, and near-exponential pressure decay in late diastole (Figure 1).

\section{Calibration}

Requirements for accurate quantitive tonometry cannot be achieved in practice because of the soft tissue which intervenes between the skin and anterior wall of the artery, but they can be approximated. Though others have been more fortunate, we have never been confident about relying on the instrument's internal calibration even for determination of wave height (pulse pressure), and prefer to calibrate systolic and diastolic pressure in the radial artery from cuff values in the brachial artery. For carotid calibration, we rely on indirect determination - either through use of transfer functions from the radial artery to ascending aorta, and then from the ascending aorta to carotid artery (see below) or through assuming that the mean and diastolic pressure are the same in the carotid artery as in the brachial and radial artery and adjusting systolic pressure accordingly. Unusually high or low systolic and pulse pressures may be recorded in the carotid artery when the transducer's internal calibration is used. Unusually high systolic carotid pressure may be a consequence of kinking, so that the whole vessel is moved towards the transducer during systole; it is most often apparent when the carotid arteries are tortuous.

\section{Aortic pressure estimation}

Synthesis of the aortic from the radial or carotid pressure wave assumes a generalized transfer function to describe arterial properties between the ascending aorta and peripheral recording site. Use of a generalized transfer function assumes that properties of the arterial system between the two sites are the same in all persons and under all conditions. Clearly this is not the case, since vascular dimensions depend on body size, and vascular properties vary with arterial pressure, with age and with therapy. If it were possible, it would be desirable to tailor the transfer function to each individual. Results however, from using a generalized transfer function are surprisingly good, and appear to approach $>90 \%$ accuracy in generating features of the ascending aortic pressure wave [17-19]. Such correspondence may be attributed to the fact that upper arm length is not very different between different adults, that upper limb pulse wave velocity changes little with age $[5,20]$ or with elevation of arterial pressure $[5,21]$ or with the types of vasoactive therapy used in clinical practice $[5$, 17]. Further, differences in upper limb properties appear to have a greater effect on the frequency of maximal amplification, where components of the pressure wave are relatively small, with far less effect at the lower frequencies whose harmonic components are greatest. The transfer functions that we have established in a small group of patients studied at cardiac catheterization [17] are similar to those that we had originally determined from aortic arch to brachial artery [22], and in those determined by a number of others at cardiac catheterization [18, 19, 23], and extrapolated from noninvasive studies [24]. These results are also similar to those calculated for our model of the upper limb circulation [25].

Validation of our own specific methods have been described by groups in Japan [26], Sweden [27], and the USA [28]. Validation studies confirm that the radial and brachial artery pressure values are very different to those in the ascending aorta especially with tachycardia, during vasodilator infusion and during interventions such as the Valsalva manoeuvre, while the calculated values for systolic, diastolic and pulse pressure fall within the range specified for the AAMI and B.H.S. requirements [29], at least for directly recorded (and calibrated) radial waveforms.

Claims for accuracy of this technique for noninvasively recorded waveforms need to be guarded. Calibration of systolic and diastolic values for the tonometric wave with a cuff sphygmomanometer relies on the innate accuracy of this method for determining intra-arterial pressure. If one accepts the innate inaccuracy of the cuff and Korotkov method for determining intra-arterial pressure [30], then use of this technique is a step forward towards greater 


\section{SphygmoCor ${ }^{\mathrm{TM}}$ \\ Aortic Blood Pressure Report}

PATIENT DATA

$\begin{array}{lllll}\text { Patient Name } & \text { S } & \text { D } & & \\ \text { Patient ID } & & & & \text { Address : } \\ \text { Patient Code } & & & \text { FEMALE } & \\ \text { Age, Sex } & 48 & & \text { FEx }\end{array}$

\section{STUDY DATA}

11 Aug 2000, 8:46:18 AM Height, Weight (BMI) $175 \mathrm{~cm}, 64 \mathrm{~kg}\left(20.9 \mathrm{~kg} / \mathrm{m}^{2}\right)$ Operator ID: Medication: irbesartan natrilix

Notes:
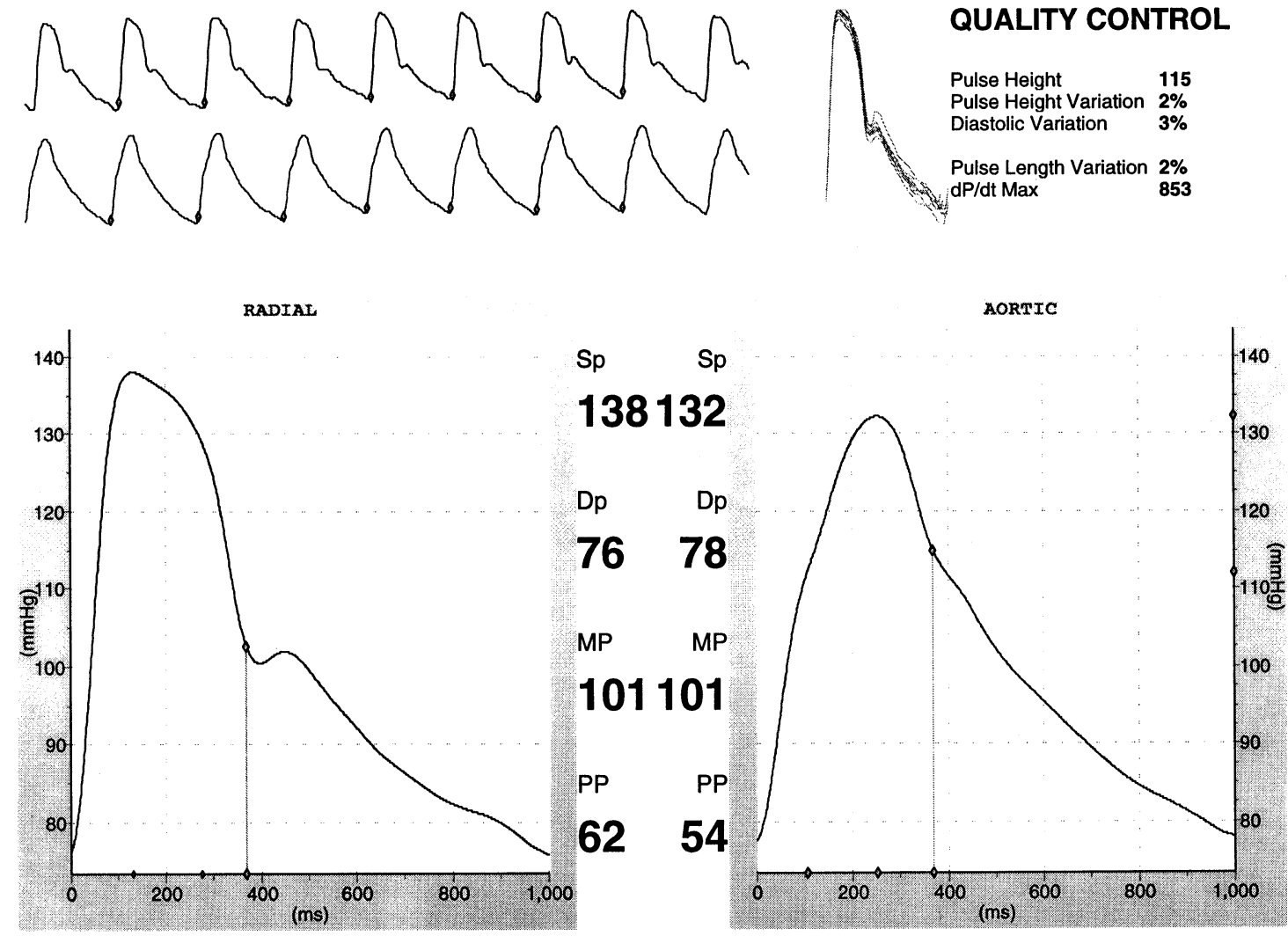

\section{CENTRAL HAEMODYNAMIC PARAMETERS}

\begin{tabular}{|c|c|c|}
\hline $\begin{array}{l}\text { te, Period } \\
\text { Duration (ED) } \\
\text { I, T2 }\end{array}$ & $\begin{array}{l}59 \mathrm{bpm}, 1023 \mathrm{~ms} \\
369 \mathrm{~ms}, 36 \% \\
105,253,136 \mathrm{~ms}\end{array}$ & $\begin{array}{l}\text { P1 Height(P1 - Dp) } \\
\text { Augmentation (AG) } \\
\text { Aug. Index (AG/PP, P2/P1) }\end{array}$ \\
\hline
\end{tabular}

PWV Medical SCOR-Vx 6.0b (00152) 100 DATA 24 Oct 2000

Figure 1 The Sphygmocardiograph: computerized report on analysis of radial artery and synthesized aortic pressure waves. A series of radial artery pressure waves, recorded over an $8 \mathrm{~s}$ period (upper continuous tracing) are used to synthesize a series of ascending aortic pressure waves (lower continuous trace) using a convolutional algorithm and a generalized transfer function which characterizes hydraulic properties of the upper limb vasculature. The radial waves are ensemble-averaged into a single wave (centre left), and the aortic waves into a single synthesized aortic wave (centre right), with the radial wave calibrated to brachial systolic and diastolic pressure, and integrated mean pressure taken to be identical at radial and aortic sites. Features of the waves (foot, shoulder, peak, incisura) are identified automatically using differentials, and flagged. The detailed report gives information relevant to ventricular/vascular interaction from both pressure and time values, as calculated from the synthesized aortic waveform. 
accuracy in determining central pressure from what currently exists.

\section{Reproducibility}

Mastery of applanation tonometry is not difficult, but it does entail training, knowledge of theoretic principles, knowledge of normal waveforms and relatively frequent use. It certainly is possible to record bizarre, and even inverted waveforms when the tonometer is not applied correctly and we have been aware of highly unusual waveforms in multicentre trials - especially from smaller centres with infrequent use. Contemporary reports (Figure 1) provide information on variability of pulse pressure and diastolic pressure and recorded waveforms as a quality control measure. We have found it helpful to compare indices from ascending aortic pressure waves derived from the carotid waveform to compare against that derived from the radial waveform when the latter is unusual or suspect.

Formal studies show good repeatability and low interobserver variation for tonometry and derived indices [31-33, Table 1]. These results accord with our own observations. Persons interested in using these techniques

Table 1 Reproducibility

Reproducibilty

1. Parker J et al. Sydney

Aortic augmentation index

$\%$ from radial

Aortic augmentation index

$\%$ from carotid

2. Liang Y et al. [31]

Aortic pulse wave

velocity $\left(\mathrm{m} \mathrm{s}^{-1}\right)$

Carotid augmentation

index (\%)

3. Wilkinson et al. [32]

\section{Brachial PWV}

Aortic PWV

Aortic augmentation

index (\%)

4. Siebenhofer et al. [33]

Aortic augmentation

index $(\%)$

Subendocardial viability

ratio (\%)

Aortic systolic pressure

Aortic diastolic pressure

0.4 s.d. 6.4

2.7 s.d. 15.4

0.1 s.d. 1.7

0.1 s.d. 0.7 are advised to undertake their own studies of reproducibility, repeatability and interobserver error, as well as comparing results from both radial arteries and from the carotids. Persons would reasonably be advised not to proceed with use of such instrumentation unless they and their technical staff could achieve results similar to those in Table 1.

\section{Effects of physiological phenomena on the arterial pulse}

\section{Growth and development}

In infants, the arterial pulse has the same contour in central and peripheral arteries, and is remarkably similar to that seen in elderly subjects. Its amplitude is of course low, but it shows no obvious secondary wave in diastole, and the peak of the wave is seen in late rather than early systole $[5,6,34,35]$. With bodily growth to late adolescence, the peripheral pulse becomes amplified compared with the central pulse, the peak of the wave moves into early systole, and the secondary diastolic wave becomes apparent in early diastole. These pressure wave changes account for the marked increase in peripheral pulse pressure and systolic pressure between infancy and late adolescence which is so apparent in population studies [36].

The curious pressure pulse waveform in infants, and paradoxical similarity to the elderly is readily explained on the basis of early return of wave reflection from peripheral to central vessels. In infants this is due to short body length, despite the aorta being very distensible and having relatively low pulse wave velocity. In the elderly, the aorta is very stiff, and its high pulse wave velocity accounts for earlier return of wave reflection despite normal adult body dimensions. Infants have relatively long left ventricular ejection periods, despite their small bodies and relatively fast heart rate $[5,35]$. Experimental animals of similar size and heart rate have much shorter ejection duration, so that secondary reflected waves are apparent in diastole rather than systole [5].

The generalized transfer function used by ourselves and others to generate ascending aortic pressure waves [17-19, $22,23]$ have been established in fully grown adults, and are not applicable to children whose shorter body lengths affect wave travel and reflection in the upper limb as well as in the trunk and lower limbs (whence arises most wave reflection). 
conducted by Kelly et al. [37], Figure 2] and show progressive increase in the late systolic pressure peak in both radial and carotid arteries, together with disappearance of the secondary diastolic pressure wave. Changes are similar at both sites, but at any age, the late systolic pressure wave is lower in the radial artery than in the carotid. Similar changes have been noted in the ascending aorta from recordings taken at cardiac catheterization, but late systolic augmentation is greater than in the carotid and far greater than in the radial artery.

Augmentation is the boost to late systolic pressure after the initial systolic shoulder, and can be expressed in $\mathrm{mmHg}$ or in relative terms as pulse pressure divided by the pressure to the first systolic shoulder, or as augmentation divided by pulse pressure. For the aortic wave in Figure 1, augmentation is measured as $20 \mathrm{mmHg}$ or as $159 \%$ (or as $37 \%$ of pulse pressure).

In late adolescence, amplitude of the ascending aortic systolic pressure wave approximates the first, with augmentation indexes around $100 \%$. This appears to increase progressively throughout life with values of around 160\% found in elderly persons. In very elderly persons, radial pressure wave augmentation is close to $100 \%$, with a secondary pressure wave of like amplitude to the first, having risen from around $40 \%$ in late adolescence.
Progressive increase in augmentation during adult life is attributable to early return of wave reflection from the trunk and lower body. Wave reflection occurs at the myriad of arterial terminations throughout the body where low resistance conduit arteries join high resistance arterioles. Early return of reflection is caused by arterial (and particularly aortic) stiffening, which increases pulse wave velocity [5]. Such aortic stiffening is apparent as increase in pulse wave velocity, which has also been demonstrated by our group in normal western subjects and in normal Chinese, who have very low prevalence of atherosclerotic disease $[5,20]$. Aortic wave velocity more than doubles between age 20 and 100 years [5,20]. This is a normal ageing phenomenon, and clearly is responsible for the increase in pulse pressure and in systolic pressure which is seen with advancing years [38]. The phenomenon is accentuated by hypertension and by arterial degeneration, and is modified by cardiac as well as by arterial disease, as discussed below.

\section{Physical fitness}

Physical fitness appears to offset considerably the ill effects of ageing on the arterial pulse [39], and to be associated with lower systolic augmentation of the pulse in different

\section{Radial pulse contour}

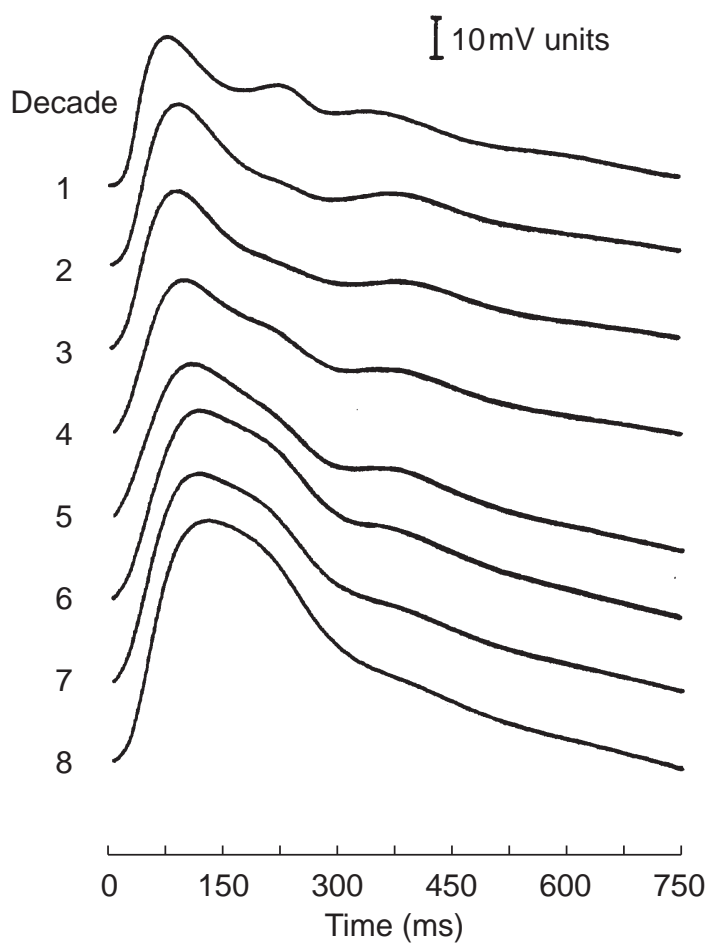

Carotid pulse contour

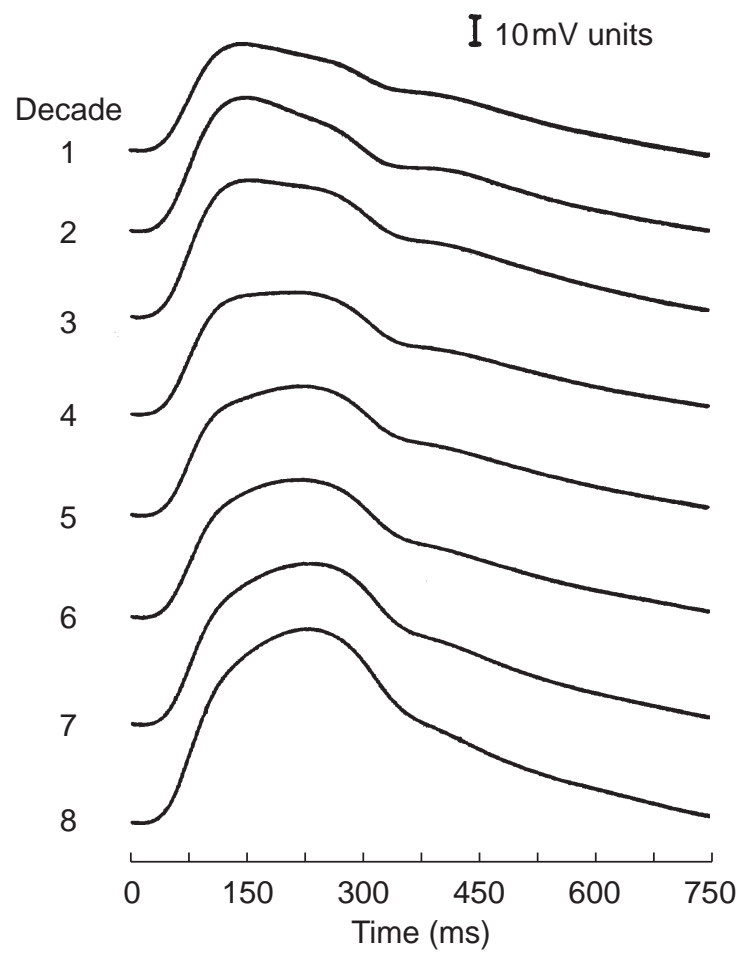

Figure 2 Change in contour and amplitude of pressure waves recorded in the radial artery (left) and carotid (right) in normal subjects between the first and eighth decade of life. Data are ensemble averaged into decades from 1005 different subjects. From Kelly et al. [37], with permission of the American Heart Association. 
arteries. This is what one might expect if exercise had a widespread effect on endothelial function throughout the body causing functional dilation of muscular conduit arteries and leading to both decrease of wave reflection and slowing of pulse wave velocity. Either could have the observed effect of decreasing augmentation of the radial, carotid and aortic pulse, but the dominant mechanism has not yet been established. Another (less likely) possibility is that persons with lesser degrees of aortic ageing change feel more comfortable during exercise than those with more, and so are more likely to participate and persevere in regular exercise.

While widespread improvement of endothelial function may explain decreased augmentation in physically fit individuals, there is no known relationship between endothelial dysfunction and pulse wave contour. The demonstrated impairment of upper limb endothelial function with age in different diseases is not associated with definite alterations in pulse wave velocity or other indices of arterial stiffness in the upper limb [5, 21, 24].

\section{Food}

Ingestion of food - even just a glucose drink, can reduce wave reflection from the splanchnic bed, and so alter the contour of the arterial pressure wave, particularly the degree of late systolic augmentation [5, 17]; this may be due to insulin release [40]. It follows that investigations of ageing, of disease, or of drug effect should be done in the post absorptive state.

\section{Heart rate}

Heart rate change alters the pattern, and especially the duration of ventricular ejection. This leads to alteration in contour of the arterial pressure wave, especially the summation of reflected waves with the incident wave generated by ventricular ejection. Augmentation increases with slowing of heart rate (through increase in ventricular ejection period leading to summation of incident and reflected wave), and decreases with increase in heart rate (and shortening of ejection period). This has been studied by Gallagher [24], and Wilkinson et al. [41], and accounts for approximately $4 \%$ decrease in aortic augmentation per 10 beats $\mathrm{min}^{-1}$ increase in heart rate during cardiac pacing. Increase in heart rate also increases amplification of the pulse wave between aorta and peripheral arteries, simply on account of the greater amplification of individual harmonics at frequencies close to the maximum of 5-6 Hz. Use of the transfer function makes allowance for this in generation of the ascending aortic from the peripheral pressure wave at different heart rates.

\section{Exercise}

The effects of heart rate are most apparent during exercise, when, with tachycardia, pulse pressure may be more than twice as great in the radial artery as in the ascending aorta, and when radial systolic pressure may be $>80 \mathrm{mmHg}$ higher [42]. During running, vertical bodily movement generates additional pressure waves that become apparent in the arterial pulse [43, 44]. It appears that in trained athletes during long distance running, a type of counter pulsation may be achieved, with heart rate and stride rate entrained, and with vertical bodily movement causing the greatest boost during diastole. Such a phenomenon could have a deleterious effect, if phase were reversed, and systolic pressure were boosted and diastolic pressure reduced [43, 44].

\section{Body height}

At any age, and for any artery, augmentation is dependent on body height, being greater in shorter than in taller persons $[45,46]$. Differences in body height largely explain differences in augmentation between males and females [47]. Short bodily stature is known to be a risk factor for cardiovascular disease. Early wave reflection with increased aortic systolic pressure augmentation, and with increased left ventricular load and left ventricular hypertrophy may be the mechanism involved [5].

\section{Gender}

While oestrogens do have acute effects on arterial stiffness, differences in pulse contour between males and females before and after the menopause can largely be explained on the basis of differences in body height [47].

\section{Effects of disease}

Arteriosclerosis (generalized degeneration of medial elements in elastic arteries)

Ageing has the most obvious and consistent effect on the arterial pulse. This is progressive from the early twenties, with gradual increase in aortic pulse wave velocity and progressively early return of wave reflection, such that the secondary wave in diastole moves into systole with greater augmentation of pressure in late systole. This has been discussed already as a physiological phenomenon since it is seen in all human subjects with ageing. The underlying cause - aortic stiffening - is caused by fracture and fragmentation of elastic lamellae within the media [5]. Increased stiffness is caused by stresses being transferred from elastin to less extensible collagen elements in the wall, and is associated with progressive aortic dilation. 
Ultimately this process results in disorganization and extreme dilation of the aorta and elastic arteries, where the media shows areas of 'medionecrosis'. This ageing change merges into a degenerative process which must be regarded as a disease and is termed arteriosclerosis. It results in progressive increase in pulse pressure and systolic pressure, which is described as isolated systolic hypertension. Late systolic pressure augmentation, caused by early wave reflection may easily account for a $40-50 \mathrm{mmHg}$ boost to systolic pressure in central arteries [5, 48].

\section{Hypertension}

Systolic hypertension may be a consequence of aortic degeneration. But hypertension can also accelerate aortic degeneration, and by itself may cause the same pressure wave changes as seen with ageing but at an earlier age. The mechanism here is acute, and reversible, and is simply due to increased stiffness and accelerated pulse wave velocity in the more tense aorta. Such change in the arterial pulse, with increased amplitude of the secondary systolic pressure wave in the radial artery, was regarded by Mahomed [7, 8] as the best evidence of elevated arterial pressure, and was so used by him in clinical studies over 20 years before the Riva-Rocci cuff method was introduced.

It appears that the upper limb generalized transfer function remains valid for generation of central from peripheral pressure in the presence of hypertension, since distensibility of the brachial artery and its radicles, and transfer function changes little with elevation of arterial pressure $[5,21,24]$.

\section{Atherosclerosis}

There are many studies describing increase in arterial stiffness in patients with coronary artery disease or with other evidence of atherosclerosis. Despite this, and despite our every opportunity, we have not been able to gauge the severity of atherosclerosis on the basis of the arterial pressure wave, and we are not aware that others have been able to accomplish this in prospective studies. We have not been able to show any definite difference in aortic pulse wave velocity in patients with generalized atherosclerosis, and can not propose this as a screening test for atherosclerosis. Neither can others who have studied this possibility [49]. Our own results for aortic pulse wave velocity were virtually identical in populations with low and high prevalence of atherosclerosis [5, 20, 50]. Atherosclerosis must stiffen the aorta, and must contribute to early wave reflection. We are surprised that it has so little effect on measured indices of arterial stiffness, or on the contour of the arterial pulse, which is so sensitive to changes in such indices.

\section{Diabetes mellitus}

As with atherosclerosis, diabetes mellitus has been described as increasing arterial stiffness. Nonetheless, determination of aortic stiffness or measurement of pulse wave contour have not been shown to aid in the diagnosis of diabetes mellitus, nor definitely proven to assist in assessment of its severity. Recent studies have shown subtle but definite increase of aortic augmentation in patients with type I [51] and type II (Brooks \& Yue, personal communication) diabetes, consistent with increase in aortic stiffness. At this point in time, it can only be said that the effects of ageing and of hypertension appear to dominate over the lesser effects on aortic stiffness and on pulse wave contour of diseases such as diabetes mellitus and atherosclerosis [52].

\section{Premature aortic degeneration}

In clinical practice, one not infrequently finds persons with substantial aortic augmentation, greater than expected for age or for level of arterial pressure. Pulses from one such subject are shown in Figure 1. In our practice, such persons are often female, middle aged, and apparently in very good health, but with an ominous family history of vascular disease. Two of the handful we have followed have already had cerebral vascular accidents before the age of 55 years. Clearly, further investigation of such persons is likely to be productive and useful. These may well confirm the description of persons with premature cardiovascular events by Mahomed [7] - 'by his pulse you will know him', and the original observations of medical examiners for life insurance companies [10].

\section{Heart failure}

In contrast to patients with uncomplicated diabetes mellitus and atherosclerosis, pulse wave analysis is useful as a screening tool in heart failure [5]. In diastolic left ventricular dysfunction, ejection duration is prolonged on account of slowed calcium re-uptake [53, 54], often in association with left ventricular hypertrophy. We have utilized this to support a diagnosis of diastolic left ventricular dysfunction in patients with cardiac failure, and to assist in the separation of this condition from systolic left ventricular dysfunction [55] (Figure 3).

In systolic left ventricular dysfunction, ejection duration is decreased on account of early wave reflection having a greater effect on flow than on pressure [56, 57]. This phenomenon accounts for the appearances of a dicrotic pulse in systolic heart failure, with ejection duration shortened, with central pressure augmentation minor or absent, and with prominence of wave reflection in diastole $[5,6,58,59]$. We have used this phenomenon to separate 


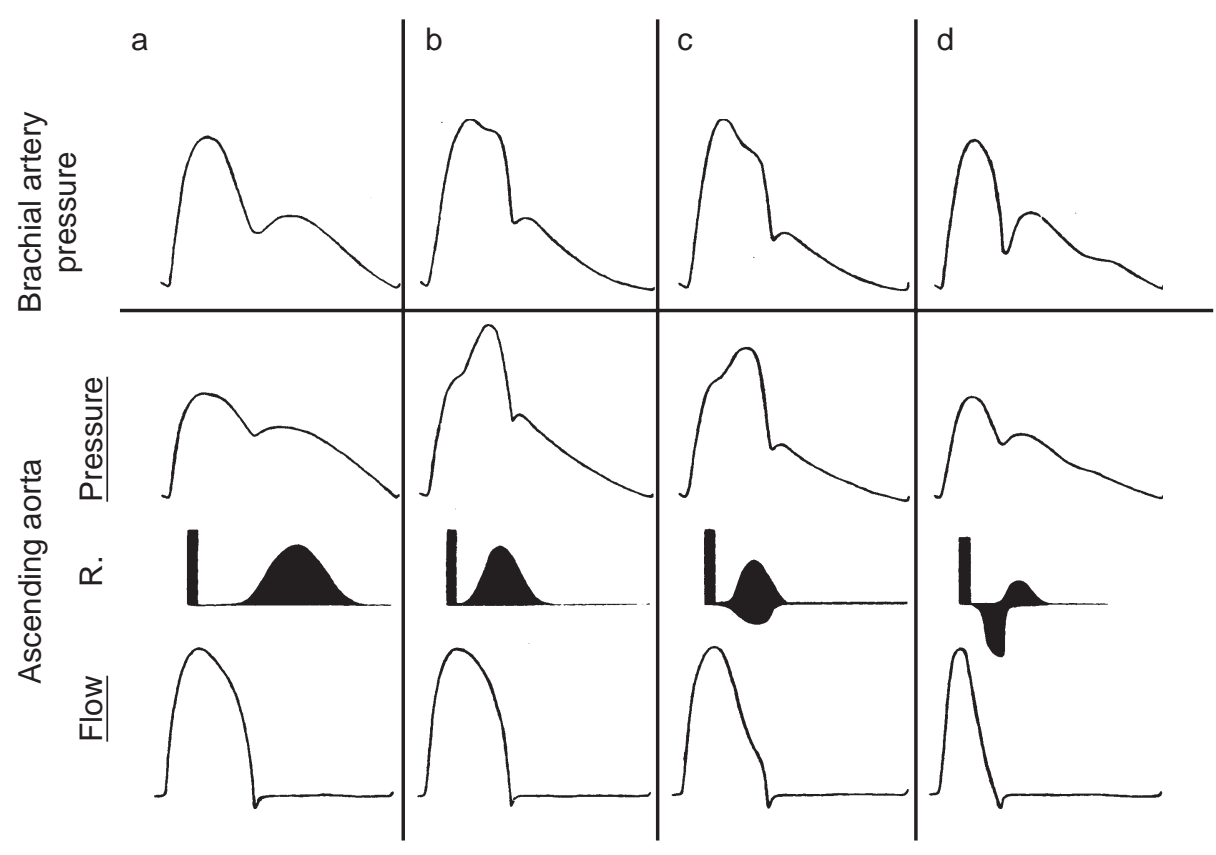

Phase I

Systolic compensation

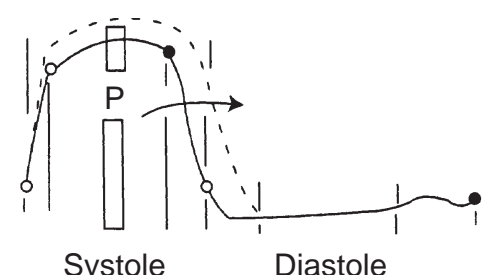

Phase II

Systolic compensation with diastolic failure

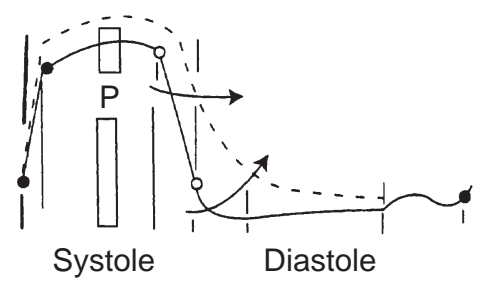

Phase III

Systolic and diastolic failure

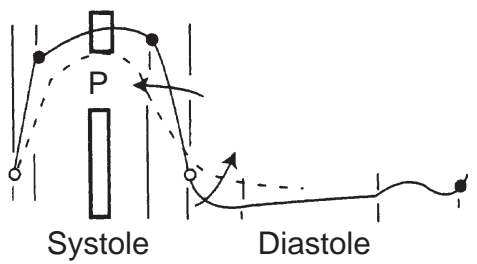

Systole

Diastole

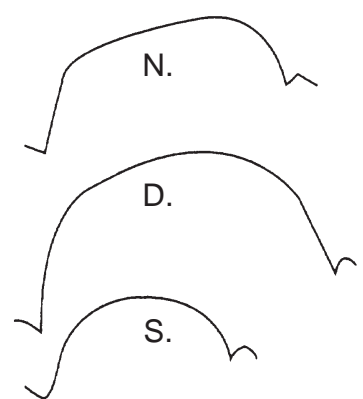

Figure 3 Above) Systolic dysfunction and heart failure. Differing effects of wave reflection (depicted on third tracing from top) on brachial and aortic pressure waves (top two tracings) and on ascending aortic flow (bottom trace) with development of elevated systolic pressure in adult life (second from left), then with development of mild and severe heart failure (third and fourth panels from left). From O'Rourke [86]. Below) Diastolic dysfunction and heart failure. Successive phases of left ventricular malfunction, associated with left ventricular hypertrophy from chronic increase in left ventricular load. Solid line is the normal left ventricular pressure tracing. With hypertrophy, there is prolongation of ventricular contraction and increase in ejection duration (phase 1). Delay in relaxation follows with increased left ventricular pressure throughout most of diastole (phase 2). With impairment of ventricular contractility (phase 3), peak systolic pressure is reduced and ejection duration is decreased, while relaxation remains prolonged, and pressure is raised throughout diastole. At bottom right are the systolic portions of the aortic pressure waves taken from these data and drawn on an expanded scale for phase 1 (normal:N), phase 2 (diastolic failure:D), and phase 3 (with onset of systolic failure:S). From Nichols \& O'Rourke [5]. After Brutsaert et al. [53] as modified by Federmann \& Hess [54]. 
systolic and diastolic dysfunction, and to gauge the severity of systolic dysfunction $[5,60]$ as well as to separate systolic from diastolic left ventricular dysfunction as the predominant cause of cardiac failure. Value is enhanced through use of glyceryl trinitrate which, through reduction in wave reflection, decreases left ventricular load and increases cardiac output and left ventricular ejection duration; capacity to increase ejection duration is related to the severity of left ventricular dysfunction [60].

\section{Effects of drugs}

Pulse wave analysis uncovers the favourable effects of vasodilator drugs which are either not apparent or not fully apparent from conventional cuff recordings of arterial pressure. Decrease in amplitude of the secondary systolic wave in the radial artery, even with maintenance of the initial peak indicates decrease in ascending aortic and left ventricular systolic pressure (Figure 4). Such a change in Murrell's radial artery tracing after nitroglycerin [61] (Figure 5), explains the antianginal effect of this drug is due at least in part to decrease in left ventricular load $[5,6,62$, 63] (Figure 4). Anggard (personal communication) uses this change to quantify effects of nitroglycerin and other vasodilators. We prefer to determine these effects from the synthesized aortic pressure pulse, partly for convenience and to provide other indices of ventricular vascular interaction, and partly because it is often not possible to identify the secondary systolic shoulder on the radial pressure wave after nitroglycerin. Anggard's approach is to measure change in relative height of the dicrotic notch in the finger photoplethysmograph.

Our initial observation of relative maintenance of peripheral systolic pressure despite considerable fall in

Control
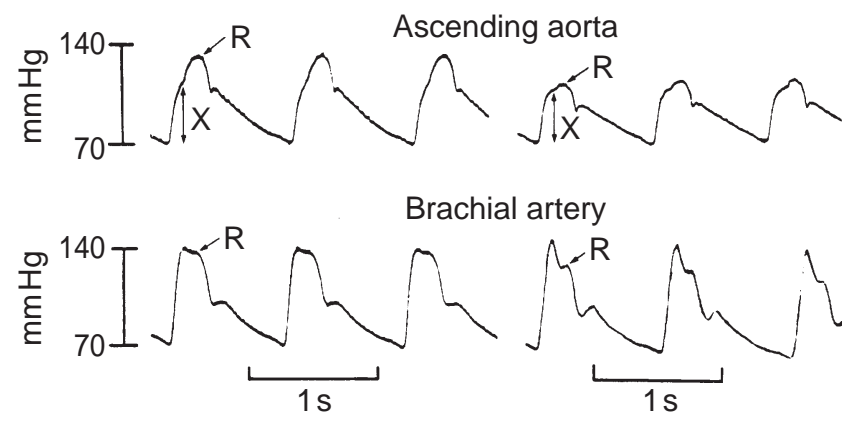

Figure 4 Effects of nitroglycerin on contour of the ascending aortic and brachial pressure waveforms. Pressure waves recorded in the ascending aorta (above), and brachial artery (below), of an adult man at cardiac catheterization under control conditions (left) and following $0.3 \mathrm{mg}$ nitroglycerine sublingually. $\mathrm{X}$ represents amplitude of the initial wave generated by ventricular ejection. $\mathrm{R}$ represents the peak of the reflected wave. From [63]. central aortic and LV systolic pressure after vasodilators such as nitroglycerin has been confirmed [64, 65], and indicates a more potent effect of such drugs on the heart than measured by conventional methods. The findings are explained on the basis of decrease in wave reflection from the lower body. The fact that brachial transfer function is little altered by nitroglycerin [17] and that the ascending aortic pressure wave during nitroglycerin infusion can

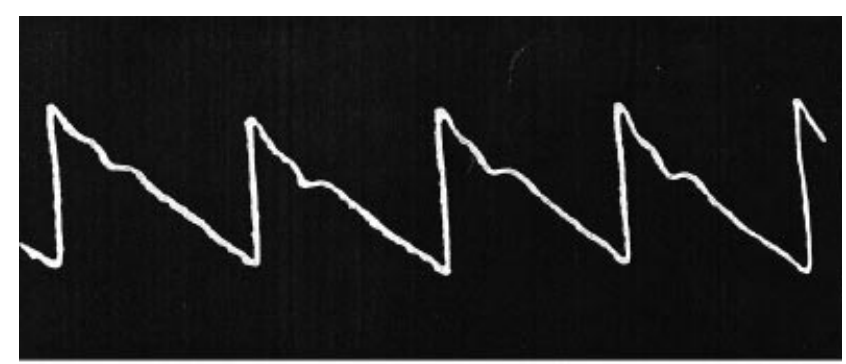

1 Before dose

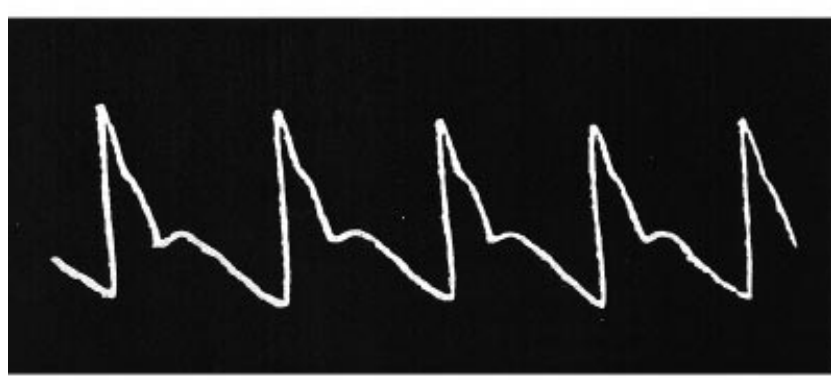

22 min after dose

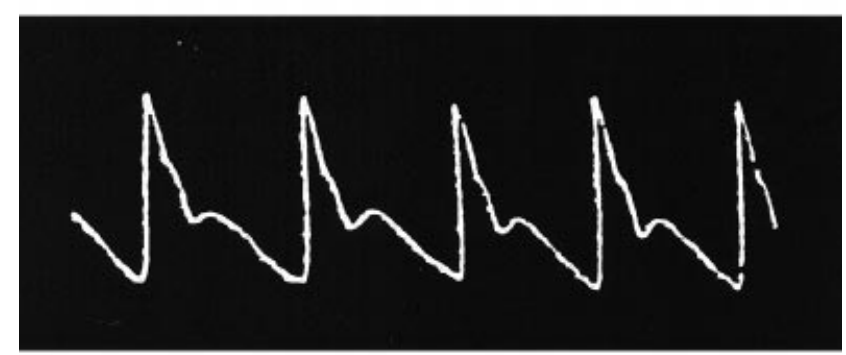

38 min after dose

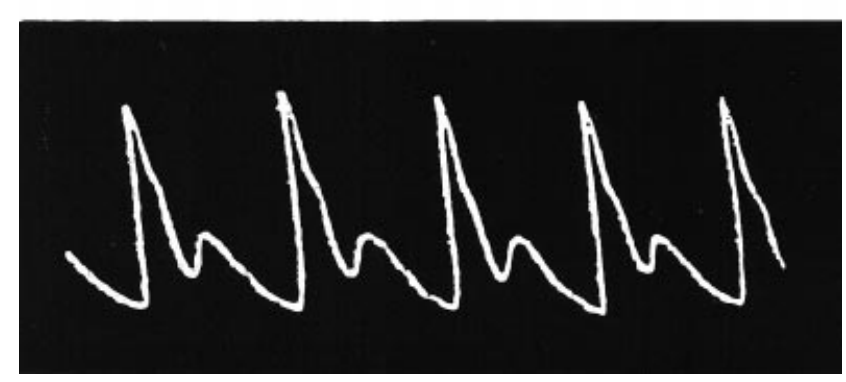

$49 \mathrm{~min}$ after dose

Figure 5 Radial artery sphygmographs showing the effects of nitroglycerin as causing progressive reduction in the late systolic shoulder of the radial artery pressure pulse. Reproduced from the first description (by Murrell in 1879) of the therapeutic value of nitroglycerin as an antianginal agent [61]. 
accurately be determined from the radial $[27,28]$ indicates that vasodilation has a lesser effect on wave reflection in the upper limb than in the lower body.

We regularly utilize the synthesized aortic pulse to monitor the effects of drug therapy in hypertension, angina pectoris, and cardiac failure. Our principal aim with drug therapy is to reduce wave reflection, and thereby to reduce aortic augmentation and so, aortic and left ventricular systolic pressure, and to optimize indices of ventricular/ vascular interaction.

In systolic failure (left ventricular failure due to impaired myocardial contractility) ejection duration of the aortic pulse waveform is shortened, as described previously; through reducing wave reflection, vasodilator agents prolong ejection and thereby increase stroke volume. Such prolongation of ejection duration can be seen on the radial, carotid, and derived aortic pulse $[5,60]$. The degree of prolongation is related to severity of cardiac failure, and has been suggested as a measure of this [60]. Japanese workers have used aortic flow waveforms to describe the ill effects of early wave reflection on the ascending aortic flow and to describe the beneficial effects of reduction in wave reflection with vasodilator agents $[66,67]$.

Pulse wave analysis is particularly useful in studying beneficial effects of nitroglycerin, since this drug in conventional doses has no detectible effects on arterioles, or on peripheral resistance. Beneficial effects in reducing wave reflections are readily explained on the basis of dilating small conduit arteries [5, 62]. At present, interaction between sildenafil (Viagra) and nitrates is of great clinical importance, and the rather draconian restrictions recommended by the joint ACC/AHA Committee [68], have been made without consideration of pulse wave analysis, and on the basis of relatively large fall of blood pressure in volunteers when full doses of each were used concurrently. Our own preliminary studies of sildenafil/ nitrate interaction, based on pulse wave analysis, carries no surprise, and suggests that sildenafil potentiates the effect of nitroglycerin approximately two fold, and prolongs this for up to 8 h [69]. Pulse wave analysis, with attention to late systolic augmentation, should provide a method for monitoring this interaction, and should permit titration of nitroglycerin (if required after sildenafil), at least by the intravenous and transdermal route.

Potential ill effects of drugs can be apparent from the arterial pressure pulse. $\beta$-adrenoceptor blocking drugs tend to increase wave reflection [70] as well as ejection duration and in some individuals cause substantial increase in central augmentation and in aortic and left ventricular systolic pressure [5]. This is rare; the beneficial effects of $\beta$-adrenoceptor blocking drugs in angina pectoris and diastolic left ventricular dysfunction are attributable to disproportionate increase in diastolic (compared with systolic) duration with bradycardia [5, 71].

Calcium channel antagonists reduce aortic systolic pressure augmentation through their vasodilator effect, and this is desirable. However, unlike nitrates, they may prolong ejection duration and decrease diastolic period, even in persons without cardiac failure [5]. This effect can predispose to angina pectoris by reducing coronary perfusion time, especially if tachycardia occurs concurrently. This effect could well explain provocation of angina and of myocardial ischaemia with short-acting dihydropyridines.

\section{Present value}

At present, we employ pulse wave analysis routinely in clinical practice. The cuff sphygmomanometer provides information only on the limits between which pressure fluctuates through the cardiac cycle in the upper limb arteries; this is distorted, inaccurate and incomplete information on left ventricular load and function. At best (with generation of the ascending aortic waveform), pulse wave analysis provides more accurate left ventricular systolic and end-systolic pressure, and ejection duration, with the ability to determine other indices of ventricular/ vascular interaction. Generation of a sphygmocardiograph report, using a hand held tonometer takes no longer than an ECG.

We find this useful in hypertension - in diagnosis and therapy. We can confirm the diagnosis of hypertension by noting the presence of substantial late systolic augmentation in the aortic pressure wave, and question the diagnosis when brachial systolic pressure is high, but this feature is not present $[1,5,7]$. We can make a diagnosis of spurious systolic hypertension of youth, sparing other investigations and lifting career restrictions that would otherwise be placed on a perfectly well young man [5, 72]. In patients with systolic hypertension we would be more concerned about a patient with substantial augmentation than one without. In patients with cardiac failure, diabetes mellitus, nephropathy, in the grey area of systolic $130-140 \mathrm{mmHg}$, a decision of when and how aggressively to treat, is aided by interpretation of the arterial pulse. In treatment itself we can gauge peripheral vasodilation from fall in mean pressure, wave reflection from fall in augmented pressure (in patients without heart failure), and beneficial effect of a $\beta$-adrenoceptor blocking drug from increase in diastolic period as well as decrease in heart rate (Figure 6).

For patients in cardiac failure, we can separate predominantly systolic from predominantly diastolic causation from wave contour and measurement of ejection duration [5]. Severity of systolic dysfunction can be gauged from contour and ejection duration, and additionally from the change induced by nitroglycerin. 

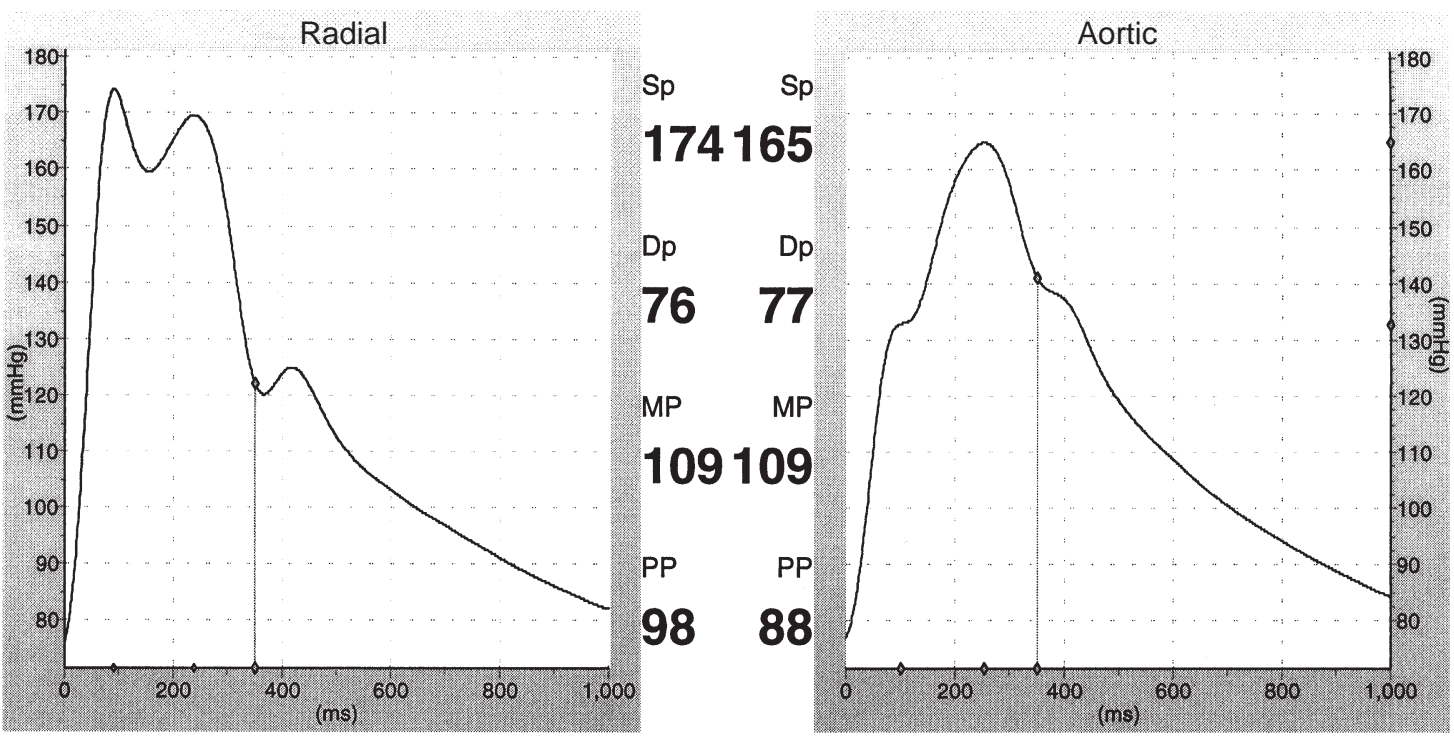

Central haemodynamic parameters

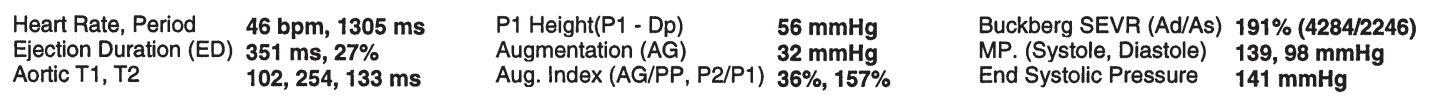

$\begin{array}{lllll}\text { Ejection Duration (ED) } 351 \mathrm{~ms}, 27 \% & \text { Augmentation (AG) } & 32 \mathrm{mmHg} & \text { MP. (Systole, Diastole) } 139,98 \mathrm{mmHg} \\ \text { Aortic T1, T2 } & 102,254,133 \mathrm{~ms} & \text { Aug. Index (AG/PP, P2/P1) } 36 \%, 157 \% & \text { End Systolic Pressure } & 141 \mathrm{mmHg}\end{array}$

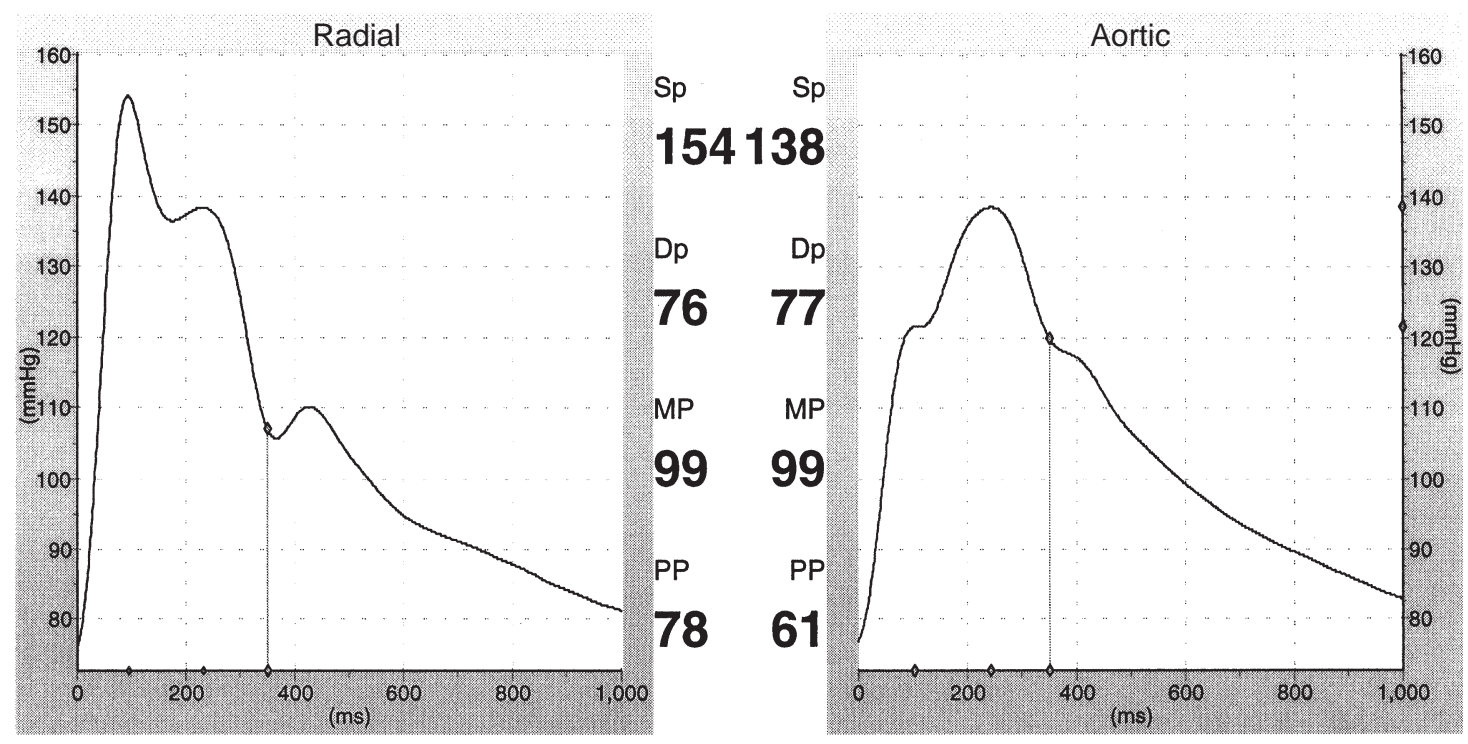

Central haemodynamic parameters

$\begin{array}{lllll}\text { Heart Rate, Period } & \mathbf{4 5} \mathrm{bpm}, 1336 \mathrm{~ms} & \text { P1 Height(P1 - Dp) } & \mathbf{4 4} \mathrm{mmHg} & \text { Buckberg SEVR (Ad/As) 210\% (4035/1923) } \\ \text { Ejection Duration (ED) } & \mathbf{3 5 1} \mathrm{ms}, \mathbf{2 6 \%} & \text { Augmentation (AG) } & 17 \mathrm{mmHg} & \text { MP. (Systole, Diastole) 122, 91 mmHg } \\ \text { Aortic T1, T2 } & \mathbf{1 0 4 , 2 4 4 , 1 3 7 \mathrm { ms }} & \text { Aug. Index (AG/PP, P2/P1) } & \mathbf{2 8} \%, \mathbf{1 3 8} \% & \text { End Systolic Pressure } 120 \mathrm{mmHg}\end{array}$

Figure 6 Sphygmocardiograph reports in a patient with hypertension above (before) and below (after) treatment with perindopril. Reduction in aortic systolic pressure of $27 \mathrm{mmHg}$ is attributable to reduction of augmentation $(17 \mathrm{mmHg})$ and of mean pressure $(10 \mathrm{mmHg})$.

In patients with angina pectoris, findings of inappropriately long duration of ejection (and short diastole) at rest or with exercise suggests that coronary narrowing may be sufficiently minor not to warrant angioplasty or bypass surgery $[5,71]$. Such a finding may argue for deferring coronary angiography, and for intensification of medical therapy. Response to such therapy can be gauged from pulse wave contour.

Other uses for pulse wave analysis are certain to be encountered in the future. We are puzzled by findings of inappropriately high augmentation in some persons, suggestions of premature arterial ageing, but have not been 
able completely to explain this from conventional risk factors. We have not yet seen anything remarkable in the pulse waves of individual patients with coronary atherosclerosis or diabetes mellitus that might assist in screening of asymptomatic persons, but recognize that such data may become available [51, Brooks \& Yue, personal communication].

\section{Epidemiological possibilities}

Possibilities are substantial, but have not been explored systematically to date. We have seen (as did Mahomed [7] and his contemporaries [10] innate cardiovascular events develop in persons with greater than expected augmentation for age (or heart rate, arterial pressure), and have noted that such persons often have adverse family histories. We believe that these persons have premature arterial degeneration that has not been uncovered by other methods. The Cornell Group [73] has shown a strong association between carotid augmentation and left ventricular hypertrophy, and are exploring the value of radial, carotid and aortic augmentation in the ongoing STRONG study. The Framingham Group reported association of pulse wave contour with stroke in 1981 [74], but with dubious technology; review with new technology is presently being undertaken at Framingham.

It is ironic that Mahomed, who first made a quantitative sphygmocardiogram, and first explored clinical utility, described the ominous prognostic implication of late systolic augmentation of the radial pulse in an asymptomatic, apparently normal individual 'by his pulse you will know him' [8]. Mahomed was in the process of arranging a multicentre cumulative clinical record in association with the British Medical Association at the time of his premature death at age 35 years. This is the forerunner of modern epidemiological studies and of the American College of Cardiology National Cardiovascular Data Registry. There is little doubt that had it proceeded, pulse waveform analysis would have been included, and as much might now be known about the arterial pulse as a prognostic tool as is known about sphygmomanometric blood pressure - a method which was introduced more than 10 years after Mahomed's death. Likewise, use of pulse wave analysis by life insurance companies lapsed when Fisher's work in 1917 established the value of the Riva Rocci technique [10].

\section{Comparison with other techniques}

While particular emphasis is given here to the most sophisticated form of pulse waveform analysis (generation of the ascending aortic pressure wave), comment needs to be made on the utility of analysing other pulse waveforms.
The radial pressure pulse contains all the basic information from which the ascending aortic pulse is generated. All that is determined quantatively from the aortic pulse can be inferred from the radial. Duration of systole and diastole are measured directly from the radial pulse, and its change with ageing and with drugs can usually be followed in the same way as the aortic, though it is more difficult to identify inflections in late systole on the radial pulse. Aortic and left ventricular systolic pressure cannot be determined, nor end systolic pressure, nor the indices from which Buckberg's subendocardial viability ratio is calculated [5, 74, 75]. Analysis of the radial pulse alone may be adequate for many, and certainly improves on sphygmomanometric measurement of brachial systolic and diastolic pressure alone.

Cohn and colleagues of Minneapolis have developed a method for analysis of the diastolic part of the peripheral pressure waveform [76]. This does not consider pulse pressure nor the period of systole, and has practical and theoretic problems. The diastolic part of the pulse is the most variable when recorded noninvasively. End systolic pressure (the beginning of diastole) is some $12 \mathrm{~mm}$ lower in the radial artery than in the aorta $[27,28]$. The method requires noninvasive calculation of cardiac output from arterial pressure and a model of the arterial tree, and seeks to unscramble the incomplete dampened fluctuation due to wave reflection from the exponential pressure decline during diastole. A commercial product has been developed and is currently under evaluation.

We use the carotid pulse waveform to check against the radial when this appears unusual. Many use the carotid pulse exclusively as a surrogate of the ascending aortic. Certainly its contour is much closer to the aortic than the radial. However it cannot be calibrated with the same degree of confidence as the radial, intra and interobserver variability is greater than the radial, and many persons find the procedure quite uncomfortable. Baro-receptors are apt to be stimulated with reflex cardiac slowing. We are also concerned about plaque disruption; though never reported in the literature, this is at least a theoretic possibility.

Doppler flow pulses are recorded from the carotid and peripheral arteries to give variable information, unavailable with tonometry, on arterial narrowing [5]. Stenosis is inferred from increased flow velocity and/or spectral broadening. The Doppler technique is particularly valuable for measuring ascending aortic flow and for exposing the characteristic patterns of late systolic reduction in flow that indicate the presence of impaired cardiac contractility and systolic heart failure [66, 67]. Unusual flow patterns may also be useful in the diagnosis of 'hypertensive' or 'idiopathic' hypertrophic cardiomyopathy [5, 77, 78].

The photoplethysmogram is widely used for measuring finger volume pulsations in intensive care wards and during operative procedures. Little attention is usually paid 
to the waveform. Takazawa et al. [79] have shown that this resembles the carotid pressure pulse, and bears a resemblance to the aortic pulse. Japanese investigators have paid particular attention to the second derivative of the finger photoplethysmograph [79], and use this as an index of vascular ageing and drug effect. This field, highly developed in Japan, warrants more attention in the western world.

\section{Strengths and weaknesses (aortic pulse derived from radial/carotid)}

The potential value of this technique is apparent from previous argument. Weakness is in validation. Special emphasis is being given to this at present by our group so that others will know what degree of confidence is warranted. Articles still appear in reputable journals claiming there is insignificant difference between aortic and brachial pressure $[80,81]$. This may be the case under control conditions in older persons such as those studied after diagnostic coronary angiography, but it does not apply to the young, nor to older persons during interventions, with tachycardia, with heart failure, or with vasodilator drug therapy. The technique described here appears to retain accuracy under a variety of interventions $[17,18,27,28]$. With respect to differences between central and peripheral systolic pressures, the most frequently quoted article [82] claimed a difference of mean 0.8 , s.d. $3.5 \mathrm{mmHg}$. One has to doubt the way that data were selected when the most recent report (which is typical of 'blinded' studies) gave a mean offset using the Korotkov method of $7 \mathrm{mmHg}$, with 95\% confidence intervals of almost $50 \mathrm{mmHg}$ [83]. Results of this study are similar to our own [30], and those of Cohn et al. [77].

In evaluating the system we have used, Cameron et al. [84] suggested that a linearized correction could be applied to determine aortic systolic pressure from brachial. Our data from over 15000 reports fits in well with those of Cameron et al. (Figure 7) but we are dissatisfied with the large scatter which has $95 \%$ confidence limits embracing $30 \mathrm{mmHg}$. Our technique, which incorporates pulse waveform, results in very close approximation of estimated to measured aortic systolic pressure, and with small scatter (Figure 7).

The greatest problem in accurate noninvasive estimation of aortic pressure relates not to the tonometric pressure wave method or convolutional process but to calibration from the sphygmomanometer cuff. Data presented here argue convincingly that the radial waveform, calibrated from intra-arterial, invasively recorded arterial pressure, can be used to generate an accurate ascending aortic pressure waveform under a variety of conditions. But the same cannot be said for calibration against the sphygmomanometer cuff. Many studies have
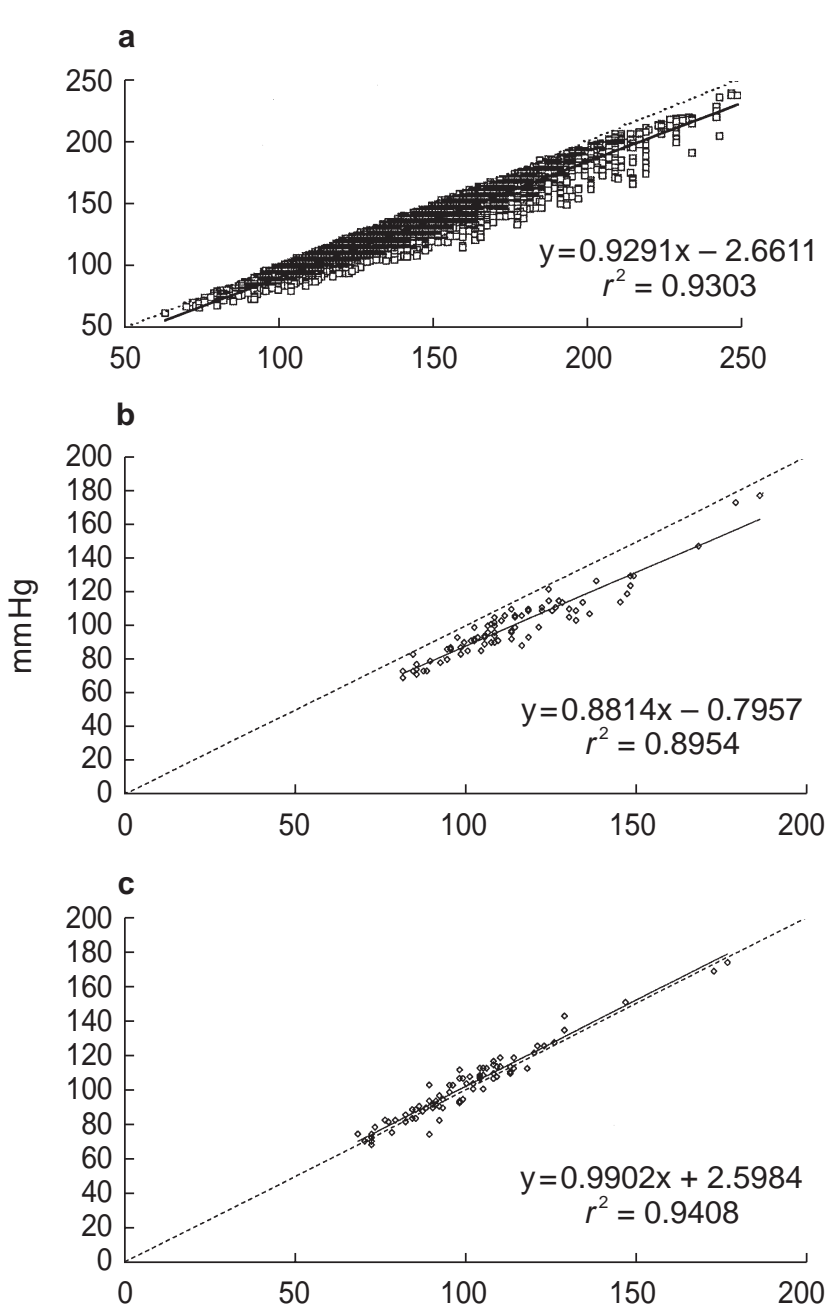

Figure 7 a) Data from 15533 separate Sphygmocor reports in 1604 different subjects/patients, showing the relationship between estimated aortic systolic pressure (ordinate $\mathrm{mmHg}$ ), and brachial artery systolic pressure, determined by conventional cuff sphygmomanometry (abscissa). b) Relationship between estimated aortic systolic pressure (ordinate) and directly measured radial artery systolic pressure (abscissa) for 80 observations under different conditions in 35 patients studied at surgery prior to initiation of cardiopulmonary bypass. c) Relationship between estimated aortic systolic pressure (ordinate) and simultaneously measured aortic systolic pressure (abscissa) for data shown in centre panel.For all, dotted line is line of identity, solid line is regression line.

shown relatively huge differences between intra-arterial and cuff blood pressure measurements [30, 77, 83]. Any attempt to determine ascending aortic pressure noninvasively will be at the mercy of cuff inaccuracies. However it may be argued that epidemiological studies have been based on the cuff method, rather than on invasive pressures, so that the former rather than the latter constitutes the 'gold standard'. If this argument were accepted, we could claim that the ascending aortic pressure waveform that we generate and indices therefrom may 
overcome some of the shortcomings of the cuff sphygmomanometer, and so improve on the information that it has provided over the past century. Such a proposition is worthy of consideration and test.

\section{Conclusions}

This review is based on Mahomed's proposition: 'Surely it must be to our advantage to appreciate fully all the pulse tells us, and to draw from the pulse all that it is capable of imparting'. But it is worth recalling William Harvey's second essay to Jean Riolan [85], and his strong views on the danger of extreme distrust on the one hand or of overenthusiasm on the other, in evaluation of a new concept.

Michael O'Rourke is a director of PWV Medical, a company developing products for pulse wave analysis.

\section{References}

1 Mahomed FA. The physiology and clinical use of the sphygmograph. Med Times Gazette 1872; 1: 62.

2 Harvey W. de Motu Cordis et Sanguinis in Animalibus 1628. William Fitzer Frankfurt. Translated by KJ Franklin. Oxford, Blackwell. 1957.

3 Bright R. Reports of medical cases selected with a view of illustrating the symptoms and cure of diseases by a reference to morbid anatomy. London, Longmans, 1827.

4 Marey EJ. Recherches sur le pouls au moyen d'un nouvel appareil enregisteur: le sphygmographe. Paris: E Thunot et Cie, 1860.

5 Nichols WW, O'Rourke MF. McDonald's blood flow in arteries, 4th edn. London: Arnold, 1998.

6 O'Rourke MF, Avolio AP, Kelly RP. The arterial pulse. Baltimore, Lea \& Febiger, 1992.

7 Mahomed F. The aetiology of Bright's disease and the prealbuminuric stage. Med Chir Trans 1874; 57: 197-228.

8 Mahomed FA. On the sphygmographic evidence of arterio-capillary fibrosis. Trans Path Soc 1877; 28: 394-397.

9 Mackenzie J. The study of the pulse: arterial, venous and hepatic, and of the movements of the heart. Edinburgh: Young J. Pentland, 1902.

10 Postel-Vinay N. The essential contribution of life insurance companies to the discovery of risk. In A century of arterial hypertension 1896-1996. New York: Wiley, 1996; pp 31-48.

11 Drzewiecki GM, Melbin J, Noordergraaf A. Arterial tonometry: review and analysis. J Biomech 1983; 16: 141-153.

12 McDonald DA. Blood flow in arteries. London: Edward Arnold, 1960.

13 Womersley JR. The mathematical analysis of the arterial circulation in a state of oscillatory motion. Dayton, Ohio: Wright Air Development Center, Technical Report Wade-TR. 56-614, 1957.

14 Kelly R, Hayward C, Ganis J, et al. Noninvasive registration of the arterial pressure pulse waveform using high-fidelity applanation tonometry. J Vasc Biol 1989; 1: 142-149.

15 Kelly R, Karamanoglu M, Gibbs H, et al. Noninvasive carotid pressure wave registration as an indicator of ascending aortic pressure. J Vasc Med Biol 1989; 1: 241-247.
16 O'Rourke MF, Gallagher DE. Pulse wave analysis. J Hypertens 1996; 14: S147-S157.

17 Karamanoglu M, O'Rourke MF, Avolio AP, et al. An analysis of the relationship between central aortic and peripheral upper limb pressure waves in man. Eur Heart J 1993; 14: 160-167.

18 Chen-Huan C, Nevo E, Fetics B, et al. Estimation of central aortic pressure waveform by mathematical transformation of radial tonometry pressure. Circulation 1997; 95: 1827-1836.

19 Fetics B, Nevo E, Chen C-H, Kass DA. Parametric model derivation of transfer function for noninvasive estimation of aortic pressure by radial tonometry. Trans IEEE July, 1999.

20 Avolio AP, Chen S-G, Wang R, et al. Effects of aging on changing arterial compliance and left ventricular load in a northern Chinese urban community. Circulation 1983; 68 : 50-58.

21 Giannattasio C, Mangoni AA, Failla M, et al. Combined effects of hypertension and hypercholesterolemia on radial artery function. Hypertension 1997; 29: 583-586.

22 O'Rourke MF. Influence of ventricular ejection on the relationship between central aortic and brachial pressure pulse in man. Cardiovasc Res 1970; 4: 291-300.

23 Lasance HAF, Wesseling KH, Ascoop CA. Peripheral pulse contour analysis in determining stroke volume. In: Progress Report 5, Inst. Med Phys. Da Costakade 45, Utrecht, Netherlands, 1976: pp 59-62.

24 Gallagher D. Analysis of pressure wave propagation in the human upper limb: Physical determinants and clinical applications.

University of New South Wales. MD Thesis, 1994.

25 Karamanoglu M, Gallagher DE, Avolio AP, et al. Pressure wave propagation in a multibranched model of the human upper limb. Am J Physiol 1995; 269 (4 Part 2): H1363-H1369.

26 Takazawa K, O’Rourke MF, Fujita M, et al. Estimation of ascending aortic pressure from radial arterial pressure using a generalised transfer function. Zeitschrift fur Kardiologie 1996; 85(Suppl 3): 137-139.

27 Soderstrom S, Nyberg J, Ponten J, Sellgren J, O'Rourke MF. Substantial equivalence between ascending aortic pressure waveforms and waveforms derived from the radial pulse using a generalised transfer function? FASEB J 1998; A712: 4131.

28 O'Rourke MF, Pauca A. Kon N, et al. Calibrated ascending aortic pressure waves can be derived from the radial pulse using a generalised transfer function. Am J Hypertens 1999; 12: (no 4, part 2): 166A.

29 White WB, Anwar YA. The importance of clinical validation of semi-automatic and automatic blood pressure monitors in adults according to national standards or guidelines. Blood Pressure Monitoring 1998; 3(Suppl 1): S7-S10.

30 Breit SN, O'Rourke MF. Comparison of direct and indirect arterial pressure measurements in hospitalised patients. Aust NZ J Med 1974; 4: 485-491.

31 Liang YL, Teede H, Kotsopoulos D, et al. Non-invasive measurements of arterial structure and function: repeatability, interrelationships and trial sample size. Clin Sci 1998; 95: 669-679.

32 Wilkinson IB, Fuchs SA, Janse LM, et al. Reproducibility of pulse wave velocity and augmentation index measured by pulse wave analysis. J Hypertens 1998; 16: 2079-2084.

33 Siebenhofer A, Kemp CRW, Sutton AJ, Williams B. The reproducibility of central aortic blood pressure measurements 
in healthy subjects using applanation tonometry and sphygmocardiography. J Human Hypertension 1999; 13: 625-629.

34 Gevers M, Hack WWM, Ree EF, et al. Arterial blood pressure wave forms in radial and posterior tibial arteries in critically ill newborn infants. J Dev Physiol 1993; 19: 179-185.

35 Hsieh K-Y, O’Rourke M, Avolio A, et al. Pressure wave contour in the ascending aorta of children - paradoxical similarity to the elderly. Aust N Z J Med 1989; 19: 555.

36 Uiterwaal CSPM, Anthony S, Launer LJ, et al. Birth weight, growth, and blood pressure: an annual follow-up study of children aged 5 through 21 years. Hypertension 1997; 30: 267-271.

37 Kelly R, Hayward C, Avolio A, et al. Noninvasive determination of age-related changes in the human arterial pulse. Circulation 1989; 80: 1652-1659.

38 Franklin SS, Gustin W, Wong ND, et al. Hemodynamic patterns of age-related changes in blood pressure: the Framingham Heart Study. Circulation 1997; 96: 308-315.

39 Vaitkevicius PV, Fleg JL, Engel JH, et al. Effects of age and aerobic capacity on arterial stiffness in healthy adults. Circulation 1993; 88: 1456-1462.

40 Westerbacka J, Wilkinson I, Cockcroft J, et al. Diminished wave reflection in the aorta. A novel physiological action of insulin on large blood vessels. Hypertension 1999; 33: 1123-1129.

41 Wilkinson IB, MacCallum H, Flint L, Cockcroft JR, Newby $\mathrm{DE}$, Webb DJ. The influence of heart rate on augmentation index and central arterial pressure. J Physiol 2000; 525: 263-270.

42 Rowell LB, Brengelmann GL, Blackman JR, et al. Disparities between aortic and peripheral pulse pressures induced by upright exercise and vasomotor changes in man. Circulation 1968; 37: 954-964.

43 O'Rourke MF, Avolio AP. Improved cardiovascular performance with optimal entrainment between heart rate and step rate during running in man. Coronary Artery Disease 1992; 3: 963-969.

44 O’Rourke MF, Avolio AP, Stelliou V, Young J. The rhythm of running: can the heart join in? Aust NZ J Med, 1993; 23: 708-710.

45 London GM, Guerin AP, Please insert one more author et al. Influence of sex on arterial hemodynamics and blood pressure: role of body height. Hypertension 1995; 26: 514-519.

46 Smulyan H, Marchais SJ, Pannier B, Guerin AP, Safar ME, London GL. Influence of body height on pulsatile arterial hemodynamic data. JACC 1998; 31: 1103-1109.

47 Hayward CS, Kelly RP. Gender-related differences in the central arterial pressure waveform. J Am Coll Cardiol 1997; 30: 1863-1871.

48 Yaginuma T, Noda T, Tsuchiya M, et al. Interaction of left ventricular contraction and aortic input impedance in experimental and clinical studies. Jap Circulation J 1985; 49: 206-214.

49 Megnien JL, Simon A, Denarie N, et al. Aortic stiffening does not predict coronary and extracoronary athersclerosis in asymptomatic men at risk for cardiovascular disease. Am J Hypertens 1998; 11: 293-301.

50 Avolio AP, Deng F-Q, Li WQ, et al. Effects of aging on arterial distensibility in populations with high and low prevalence of hypertension: comparison between urban and rural communities in China. Circulation 1985; 71: 202-210.

51 Brooks B, Molyneaux L, Yue DK. Augmentation of central arterial pressure in type I diabetes mellitus. Diabetes Care 1999, in press.

52 Breithaupt-Grogler, K, Belz, GG. Epidemiology of the arterial stiffness. Pathologie Biologie 1999; 47: 604-613.

53 Brutsaert DL, Sys SU, Gillebert TH. Diastolic failure: pathophysiology and therapeutic implications. J Am Coll Cardiol 1993; 22: 318-325.

54 Federmann M, Hess OM. Differentiation between systolic and diastolic dysfunction. Eur Heart J 1994; 15(Suppl D): 2-6.

55 O'Rourke MF, Lei J. Separation of systolic from diastolic dysfunction as a cause of cardiac failure by analysis of the arterial pulse wave. Aust NZ J Med 1997; 28: 114.

56 O'Rourke MF. Arterial hemodynamics and ventricular-vascular interaction in hypertension. Blood Pressure 1993; 3: 33-37.

57 Westerhof N, O'Rourke MF. The hemodynamic basis for the development of left ventricular failure in systolic hypertension. J Hypertension 1995; 13: 943-952.

58 Ewy GA, Rios JC, Please insert one more author et al. The dicrotic arterial pulse. Circulation 1969; 39: 655-661.

59 Lewis $\mathrm{T}$. The factors influencing the prominence of the dicrotic wave. J Physiol (Lond) 1906; 34: 415-419.

60 Uebaba K, O'Rourke MF, Keogh A, Macdonald P, Sindone A. Change in radial pulse wave contour with glyceryl nitrate as a method to assess severity of left ventricular falure. Circulation 1999; 33: 211A.

61 Murrell W. Nitroglycerin as a remedy for angina pectoris. Lancet 1879; 80: 80-81, 113-115, 151-152, 225-227.

62 Yaginuma T, Avolio AP, O'Rourke MF, et al. Effect of glyceryl trinitrate on peripheral arteries alters left ventricular hydraulic load in man. Cardiovasc Res 1986; 20: 153-160.

63 Kelly RP, Gibbs HH, O'Rourke MF et al. Nitroglycerin has more favourable effects on left ventricular afterload than apparent from measurement of pressure in a peripheral artery. Eur Heart J 1990; 11: 138-144.

64 Simkus GJ, Fitchett DH. Radial arterial pressure measurements may be a poor guide to the beneficial effects of nitroprusside on left ventricular systolic pressure in congestive heart failure. Am J Cardiol 1990; 66: 323-326.

65 Takazawa K, Tanaka N, Takeda K, et al. Underestimation of vasodilator effects of nitroglycerin by upper limb blood pressure. Hypertension 1995; 26: 520-523.

66 Miyashita H, Ikeda U, Tsuruya Y, et al. Non-invasive evaluation of the influence of aortic wave reflection on left ventricular ejection during auxotonic contraction. Heart Vessels 1994; 9: 30-39.

67 Sakai T, Takazawa K, Maeda K, et al. Changes in flow velocity pattern in the left ventricular outflow tract after vasoconstriction and vasodilation assessed by Doppler echocardiography. J Cardiol (Japan) 1992; 50: 712-726.

68 Cheitlin MD, Hutter AM, Brindis RG, et al. Use of sildenafil (Viagra) in patients with cardiovascular disease. The ACC/AHA Expert Consensus Document Circulation 1999; 99: 168-177.

69 O'Rourke MF. Potential for use of pulse wave analysis in determining the interaction between sildenafil and glyceryl trinitrate. Fourteenth Scientific Meeting Am Soc Hypertension, New York Am J Hypertension 1999; 12: ( no 4, part 2): 123A. 
70 Chen CH, Ting CT, Lin SJ, et al. Different effects of fosinopril and atenolol on wave reflections in hypertensive patients. Hypertension 1995; 25: 1034-1041.

71 Boudoulas H. Systolic time intervals. Eur Heart J 1990; 11(Suppl 1): 93-104.

72 O'Rourke MF, Vlachopoulos C, Graham R. Spurious systolic hypertension in youth. Vascular Medicine 2000; 5: 141-145.

73 Saba PS, Roman MJ, Pini R, et al. Relation of arterial pressure waveform to left ventricular and carotid anatomy in normotensive subjects. JACC 1993; 22: 1873-1880.

74 Kannel WB, Wolf PA, McGee DL, et al. Systolic blood pressure, arterial rigidity and risk of stroke: the Framingham Study. J Am Med Ass 1981; 245: 1225-1229.

75 Buckberg GD, Fixler DE, Archie JP, et al. Experimental subendocardial ischemia in dogs with normal coronary arteries. Circulation Res 1972; 30: 67-81.

76 Cohn JN, Finkelstein S, McVeigh G, Morgan D, LeMay L, Robinson J, Mock J. Noninvasive pulse wave analysis for the early detection of vascular disease. Hypertension 1995; 26: 503-508.

77 Murgo JP, Alter BR, Dorethy JF, et al. Dynamics of left ventricular ejection in obstructive and nonobstructive hypertrophic cardiomyopathy. J Clin Invest 1980b; 66: 1369-1382.

78 O’Rourke MF, Mancia G. Arterial stiffness (Invited editorial). J Hypertension 1999; 17: 1-4.

79 Takazawa K, Tanaka N, Fujita M, et al. Assessment of vasoactive agents and vascular aging by the second derivative of photoplethysmogram waveform. Hypertension 1998; 32: 365-370.
80 Marcus RH, Korcarz C, McCray G, et al. Noninvasive method for determination of arterial compliance using doppler echocardiography and subclavian pulse tracings; validation and clinical application of a physiological model of the circulation. Circulation 1994; 89: 2688-2699.

81 Teede HJ, Liang Y-L, Shiel LM, McNeil JJ, McGrath BP. Hormone replacement therapy in postmenopausal women protects against smoking-induced changes in vascular structure and function. J Am Coll Cardiol 1999; 34: 131-137.

82 Borow KM, Newburger JW. Noninvasive estimation of central aortic pressure using the oscillometric method for analyzing systemic artery pulsatile blood flow: Comparative study of indirect systolic, diastolic, and mean brachial artery pressure with simultaneous direct ascending aortic pressure measurements. Am Heart J 1982; 103: 879-886.

83 Watson S, Wenzel RR, di Matteo C, Meier B, Luscher TF. Accuracy of a new wrist cuff oscillometric blood pressure device. Am J Hypertens 1998; 11: 1469-1474.

84 Cameron J, McGrath B, Dart A. Use of radial artery applanation tonometry and a generalized transfer function to determine aortic pressure augmentation in subjects with treated hypertension. JACC 1998; 32: 1214-1220.

85 Harvey W. A second essay to Jean Riolan. In William Harvey: The circulation of the blood and other writings ed Franklin J. Dutton, New York, 1963.

86 O'Rourke MF. Arterial hemodynamics and ventricular-vascular interaction in hypertension. Blood Pressure 1994; 3: 33-37. 